\title{
Biomolecule structure characterization in the gas phase using mass spectrometry
}

\author{
Brian Bothner, Laurie Carmitchel, Kristin Staniszewski, Martin Sonderegger and \\ Gary Siuzdak* \\ The Scripps Center for Mass Spectrometry and Department of Molecular Biology, The Scripps \\ Research Institute, 10550 North Torrey Pines Road, La Jolla, CA 92037, USA
}

\begin{abstract}
Carbohydrate/cation interactions were examined in the gas phase using mass spectrometry and the results were compared with computer generated models of the complexes. Monosaccharide/alkali cation complexes of five carbohydrates, D-fructose, D-glucose, D-galactose, D-mannose, and a deuterated analog of D-glucose, 6,6-D-glucose-d $\mathrm{d}_{2}$, were studied. Among the technuques used in this effort were electrospray ionization (ESI), desorption/ionization on silicon (DIOS), matrix-assisted laser desorption/ionization (MALDI) and fast atom/ion bombardment (FAB) mass spectrometry. A series of ESI, DIOS, MALDI and FAB-MS experiments were used to obtain relative cation binding preferences of each monosaccharide. Heterodimers of 6,6D-glucose- $\mathrm{d}_{2}$ formed with each of the monosaccharides show that $\mathrm{Na}^{+}$binding for D-fructose, D-mannose and D-galactose is similar, while D-glucose was $25 \%$ weaker. Modeling studies and energy minimization calculations on the alpha and beta forms of the monosaccharide alkali cation complexes are consistent with the experimental data and indicate that D-fructose, D-galactose, and D-mannose undergo tridentate and tetradentate binding with $\mathrm{Na}^{+}$and $\mathrm{Li}^{+}$while $\mathrm{D}$-glucose would only form a bidentate complex.
\end{abstract}

\section{Introduction}

Alkali cations and carbohydrates are important physiological partners in transport processes. Carbohydrate/cation interactions play a role in protein transport across cell membranes [1,2] and cations help maintain appropriate physiological conditions in regions surrounding transport, thus facilitating the binding of simple sugars to membrane proteins. There have been numerous investigations concerning cationmediated sugar transport [3] and it has been observed that carbohydrates act as regulators in monovalent cation transport systems like the ubiquitous $\mathrm{Na} / \mathrm{K}$ ATPase [4] or the recent discovery [1] of a Na/Dgalactose symport system in a cell strain of Vibrio parahaemolyticus. There is also evidence of discrete monosaccharide-cation co-transport which has been shown to be highly dependent on which cation is present [5]. Still, the basic mechanisms of carbohydrate/cation interactions are not clearly understood, especially those interactions involving the simplest sugars, monosaccharides. Recent results using mass spectrometry to study noncovalent interactions [6-10] suggest that this technology is also well suited toward answering questions concerning cation/monosaccharide interactions.

Numerous molecule/cation complexes have been studied with desorption [11-16] and electrospray ionization [17,18] mass spectrometry (ESI-MS). For instance, multidentate association of alkali metal ions have been observed with organometallics [14], peptides [15], permethylated saccharides $[19,20]$, and oligosaccharides [21-23]. Previous desorption mass analysis experiments performed on monosaccharides used permethylated derivatives to help retain a rigid conformation [24].

\footnotetext{
${ }^{*}$ Corresponding author. E-mail: siuzdak@ scripps.edu.
} 
In an effort to gain insight into the nature of the carbohydrate/alkali cation complex under native conditions, our experiments were performed with un-derivatized monosaccharides and focused on cation binding rather than chiral interactions as in previous work [24-26]. Though little is known about the interaction of alkali cations and sugars [27-29], recent results indicate that this association may be stronger than originally inferred [30,31]. The goal of this study was to then examine the nature of this complex employing fast atom/ion bombardment (FAB), desorption/ionization on silicon (DIOS), matrix-assisted laser desorption/ionization Fourier transform mass spectrometry (MALDI-FTMS), ESI-MS, and ESI tandem mass spectrometry. The binding between alkali metal ions and five carbohydrates, D-glucose, Dgalactose, D-mannose, D-fructose, and a deuterated analog of glucose, 6,6-D-glucose- $\mathrm{d}_{2}$, were studied.

\section{Results and discussion}

Electrospray ionization (ESI) tandem mass spectrometry experiments were performed on the alkali cation/monosaccharide complex. ESI allowed for the generation of the gas phase complex, while collision-induced dissociation with tandem mass spectrometry was used to dissociate the complex and observe fragment ions. The monosaccharide/cation complexes of $\mathrm{Na}^{+}, \mathrm{K}^{+}, \mathrm{Rb}^{+}$, and $\mathrm{Cs}^{+}(\mathrm{m} / z 203$, 219, 265, and 313, respectively) generated a distinctive fragmentation pattern (Fig. 1) which dissociated to produce only the alkali cation with no significant cleavage of covalent bonds. $\mathrm{The}^{+}{ }^{+}$complex produced a significant amount of covalent bond cleavage, and these experiments were limited by the $m / z$ range in the ESI instrumentation such that $\mathrm{Li}^{+}$could not be detected and thus precluded comparison to the other cation complexes.

The importance of monosaccharide conformation, especially glucose, for complex formation was observed in these initial fragmentation studies. In order to make qualitative comparisons between the monosaccharides and their respective binding affinity of the different cations, the MS/MS experiments were performed on each complex, and as seen in Fig. 1 the data of all four monosaccharides followed a similar trend. The three monosaccharides, D-galactose, D-fructose, and D-mannose, generated the following monosaccharide/cation-to-cation intensity ratios: $80( \pm 4) \%$ for $\mathrm{Na}^{+}, 45( \pm 4) \%$ for $\mathrm{K}^{+}$, $10( \pm 3) \%$ for $\mathrm{Rb}^{+}$, and $10 \%( \pm 3)$ for $\mathrm{Cs}^{+}$. Qualitatively, this data suggests that as the cation's atomic radius increases, the association with its host monosaccharide decreases. Previous work $[22,32,33]$ describing sugar cation binding has shown effective binding to be highly dependent on the ionic radius of the cation. Crown ether-alkali metal ion association studies also indicate that multidentate binding is dependent on the size of the cations [34] (radii of $\mathrm{Li}=0.76 \AA$, $\mathrm{Na}=1.02 \AA, \mathrm{K}=1.38 \AA, \mathrm{Rb}=1.52 \AA$, and $\mathrm{Cs}=1.67 \AA$ ). Interestingly, D-glucose exhibited a similar dependence on cation size when compared to the other three monosaccharides, however glucose did not have the same affinity for $\mathrm{Na}^{+}$. D-glucose/cation complex-to-cation intensity ratios were $50( \pm 4) \%$ for $\mathrm{Na}^{+}, 45( \pm 4) \%$ for $\mathrm{K}^{+}$, $10( \pm 4) \%$ for $\mathrm{Rb}^{+}$, and $10( \pm 3) \%$ for $\mathrm{Cs}^{+}$. This difference between glucose and the other three monosaccharides indicates that their different isomeric conformations [19-21,35] were also influencing the ability of the alkali ions to complex the monosaccharides resulting in preferential cation binding.

The next experiments were designed to further investigate preferential cation binding and to take advantage of the dimerization that occurs between the monosaccharides and the alkali cations. Homodimers were detected with a $m / z 383$ corresponding to [2 D-glucose $+\mathrm{Na}^{+}$. Tandem mass analysis experiments were designed to then reveal binding characteristics between the different monosaccharides. For example, the D-fructose and D-glucose dimer complex [D-glucose $+\mathrm{D}$-fructose $+\mathrm{Na}]^{+}$was subjected to tandem mass analysis and the resulting fragment ions [D-fructose $+\mathrm{Na}]^{+}$or $[\mathrm{D} \text {-glucose }+\mathrm{Na}]^{+}$ 

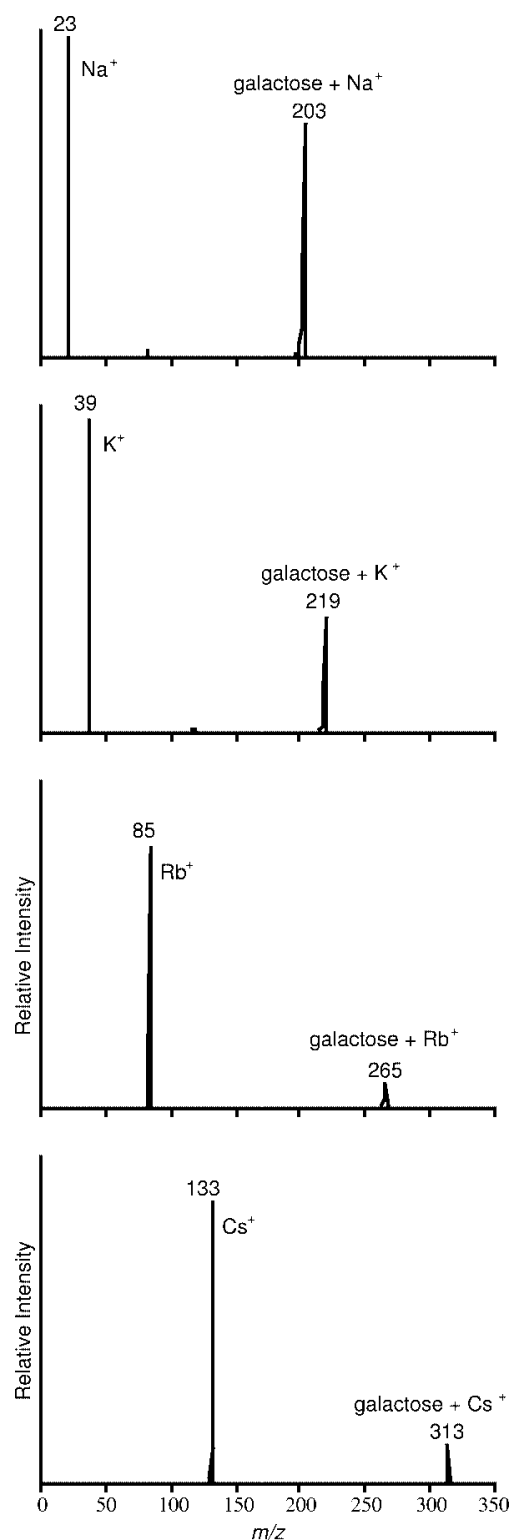

Fig. 1. Electrospray tandem mass spectrometry was used to generate fragmentation patterns of the D-galactose-alkali cation complexes. The fragmentation data was generated under identical collision-induced dissociation conditions, so the differences in relative ion intensities reflect the relative binding affinity between D-galactose and the cation. The D-galactose binding affinity to the cations followed the progression: $\mathrm{Na}>\mathrm{K}>\mathrm{Rb} \geqslant \mathrm{Cs}$.

were monitored. Based on the signal intensity of the fragments a qualitative accessment of the monosaccharide alkali cation affinity relative to the glucose alkali cation affinity could be determined. Since the monosaccharides all have the same mass (180 Da), these experiments presented a logistic problem in that the fragmentation of the homo- or heterodimers would provide no distinguishing mass information.

In order to overcome this limitation, a deuterated analog of D-glucose, 6,6-D-glucose- $\mathrm{d}_{2}$, with a mass of $182 \mathrm{Da}$ was employed. The heterodimer formed between 6,6-D-glucose- $\mathrm{d}_{2}$ and either D-galactose, 

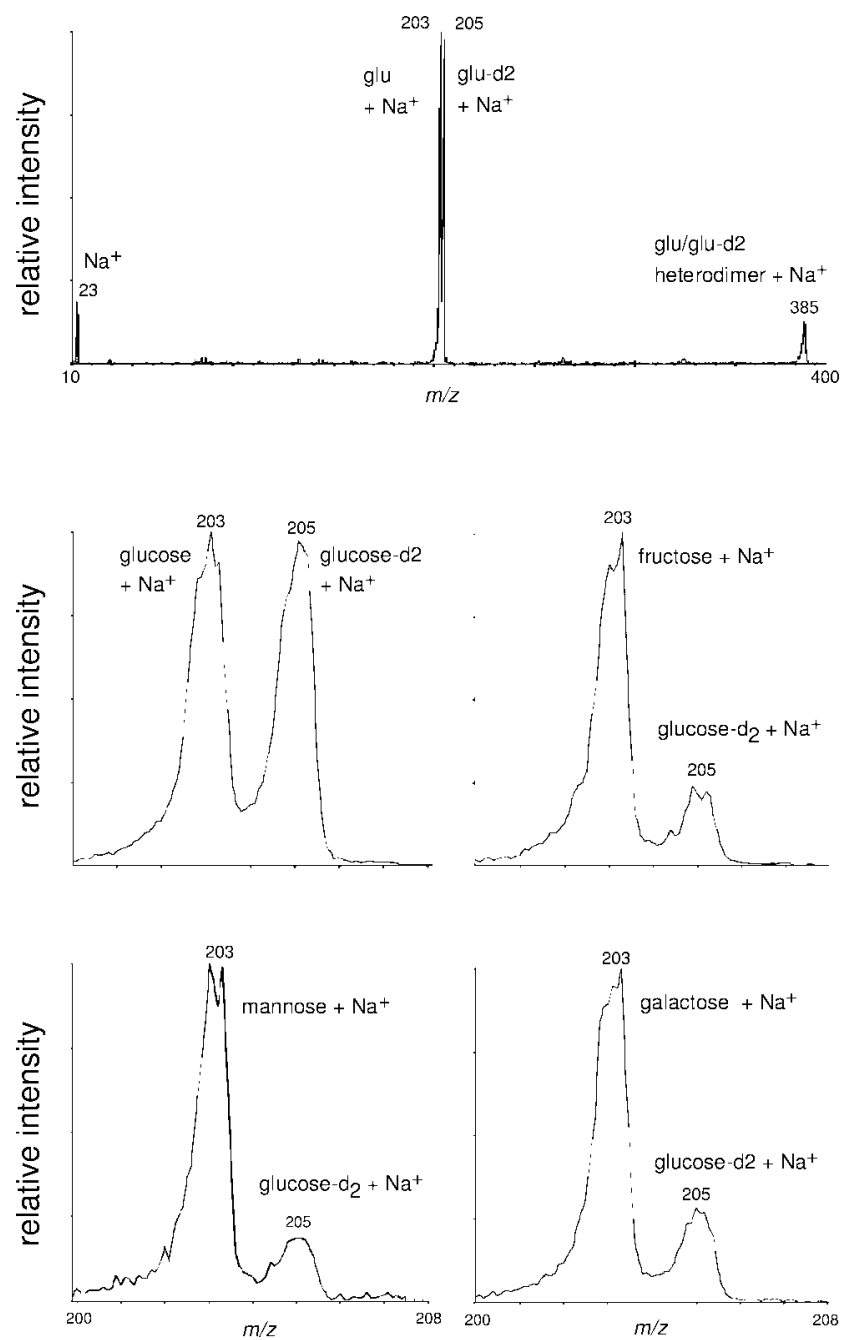

Fig. 2. Electrospray mass spectra comparing the sodium cation affinity of glucose and its isomers, fructose, galactose and mannose. Top: An electrospray tandem mass spectrum of the heterodimer (D-6,6-glucose- $\mathrm{d}_{2}+\mathrm{D}$-glucose $+\mathrm{Na}^{+}, m / z 385$ ). Bottom four: Close-ups of the heterodimer fragmentation spectra demonstrating deuterated and non-deuterated glucose have equal affinity for the sodium cation while D-fructose, D-mannose, and D-galactose have a significantly greater affinity for $\mathrm{Na}^{+}$.

D-glucose, D-mannose, or D-fructose generated distinguishable fragment ions in the tandem mass analysis experiments corresponding to [monosaccharide + cation $]^{+}$or [6,6-D-glucose- $\mathrm{d}_{2}+$ cation $]^{+}$. By comparing the ion signal intensity of both fragments, the heterodimer constituent with the strongest affinity for the alkali cation could then be determined.

The fragmentation analysis of the heterodimer/cation complex produced the [monosaccharide + cation $]^{+}$, [6,6-D-glucose- $\mathrm{d}_{2}+$ cation $^{+}$, and the parent ion, [monosaccharide $+6,6-\mathrm{D}$-glucose- $\mathrm{d}_{2}+$ cation ${ }^{+}$(Fig. 2). The $m / z$ ratios of the complexes [6,6-D-glucose- $\mathrm{d}_{2}+$ monosaccharide + cation $]^{+}$ were $369,385,401,447$, and 495 for $\mathrm{Li}^{+}, \mathrm{Na}^{+}, \mathrm{K}^{+}, \mathrm{Rb}^{+}$, and $\mathrm{Cs}^{+}$, respectively. In the case of $\mathrm{Rb}^{+}$, the $m / z$ ratio of 449 representing [monosaccharide $+6,6$-D-glucose- $\mathrm{d}_{2}+{ }^{85} \mathrm{Rb}$ ] ${ }^{+}$was selected for the MS/MS analysis to rule out the possibility of $\left[2 \text { monosaccharide }+{ }^{87} \mathrm{Rb}\right]^{+}$which has a $\mathrm{m} / z$ of 447 like the heterodimer ${ }^{85} \mathrm{Rb}$ complex. The $\mathrm{K}^{+}, \mathrm{Rb}^{+}$and $\mathrm{Cs}^{+}$complexes generated very weak het- 
Table 1

Monosaccharide cationization, intensity of each monosaccharide/cation complex relative to [6,6-D-glucose- $\mathrm{d}_{2}+$ cation $]^{+}$generated in the FAB-MS experiments. DIOS-MS experiments also produced results (within experimental error) comparable to these

\begin{tabular}{lcccc}
\hline & D-Glucose & D-Mannose & D-Galactose & D-Fructose \\
\hline$[\mathrm{M}+\mathrm{Li}]^{+}$ & 1.02 & 1.65 & 1.40 & 1.79 \\
{$[\mathrm{M}+\mathrm{Na}]^{+}$} & 0.97 & 1.54 & 1.25 & 1.72 \\
{$[\mathrm{M}+\mathrm{K}]^{+}$} & 1.03 & 1.13 & 1.00 & 1.01 \\
{$[\mathrm{M}+\mathrm{Rb}]^{+}$} & 1.05 & 1.00 & 1.03 & 0.98 \\
{$[\mathrm{M}+\mathrm{Cs}]^{+}$} & 0.95 & 1.01 & 0.98 & 1.04 \\
\hline Error $( \pm)$ & 0.04 & 0.03 & 0.04 & 0.02 \\
\hline
\end{tabular}

erodimer/cation signals with no determinable preference for either monosaccharide. It could be speculated that the size of these cations limited their ability to be effectively complexed and thus generated relatively weak nonspecific association. In contrast, the MS/MS analysis of the $\mathrm{Li}^{+}$and $\mathrm{Na}^{+}$heterodimer complexes demonstrated preferential association.

The non-covalent heterodimer was dissociated in the collision cell to form the monosaccharide-cation complexes. Affinity for the cation was based on the ratio of the peak intensities of the monosaccharide/cation complexes. The heterodimer [D-glucose +6 ,6-D-glucose- $\left.\mathrm{d}_{2}+\mathrm{Na}\right]^{+}$dissociated to produce both [D-glucose $+\mathrm{Na}]^{+}$and [6,6-D-glucose- $\left.\mathrm{d}_{2}+\mathrm{Na}\right]^{+}$at equal intensities, as expected from their identical structure. However, the deuterated isomer demonstrated only a $25( \pm 4) \%$ affinity for the $\mathrm{Na}^{+}$when compared to the other monosaccharides (Fig. 2). Experiments performed by varying the collisional energies generated comparable affinities within experimental error. In addition, D-fructose, D-galactose, and D-mannose showed no appreciable difference in their affinities for $\mathrm{Na}^{+}$; small fluctuations from run to run were within experimental error. Nearly identical results were obtained with $\mathrm{Li}^{+}$. The lower [6,6-D-glucose- $\mathrm{d}_{2}+\mathrm{Na}$ (or Li)] $]^{+}$fragment ion intensity was attributed to a lower $\mathrm{Na}^{+}$and $\mathrm{Li}^{+}$binding affinity for D-glucose, a result consistent with the previous set of experiments in which glucose had a lower affinity for $\mathrm{Na}^{+}$. This indicates that the D-glucose structure is sufficiently different from the other monosaccharide structures and is less effective in $\mathrm{Na}^{+}$or $\mathrm{Li}^{+}$binding.

FAB-MS, DIOS-MS and MALDI-FTMS experiments were carried out to further examine the binding preferences of the monosaccharides to the cations. In these experiments a solution was prepared containing equimolar quantities of 6,6-D-glucose- $\mathrm{d}_{2}$ and either D-glucose, D-fructose, D-galactose, or D-mannose and an alkali cation. Direct competition was observed for alkali cationization by monitoring the intensities of the cation adducts of each saccharide $\left([\mathrm{m} / z=180+\text { cation }]^{+}\right.$with 6,6 -glucose- $\mathrm{d}_{2}$ $\left.[m / z=182+\text { cation }]^{+}\right)$. As expected, the ratio of the intensities for the cationized glucose and 6,6-Dglucose- $\mathrm{d}_{2}$ ions were $1: 1$ for all the alkali cations, within experimental error. However when D-mannose, D-galactose, or D-fructose were analyzed in the presence of 6,6-D-glucose- $\mathrm{d}_{2}$, the former monosaccharides gave significantly greater $\mathrm{Na}^{+}$and $\mathrm{Li}^{+}$adduct ion signals, the FAB results are summarized in Table 1.

In addition to the experimental data generated on D-galactose, D-mannose, D-fructose, and Dglucose/cation complexes, molecular modeling calculations were also performed on these systems. Space filling models as well as energy minimization calculations of the monosaccharide constructs (based on their solution phase structure [36]) revealed that $\beta$-D-galactose, $\beta$-D-mannose, and $\beta$-D-fructose bound $\mathrm{Na}^{+}$and $\mathrm{Li}^{+}$through a tetradentate complex while $\beta$-D-glucose used a tridentate complex (Fig. 3). The same calculations for $\mathrm{Na}^{+}$and $\mathrm{Li}^{+}$on the $\alpha$ isomers were consistent with a tridentate complex for $\alpha$-Dgalactose and $\alpha$-D-mannose and a tetradentate complex with $\alpha$-D-fructose, while $\alpha$-D-glucose formed a 

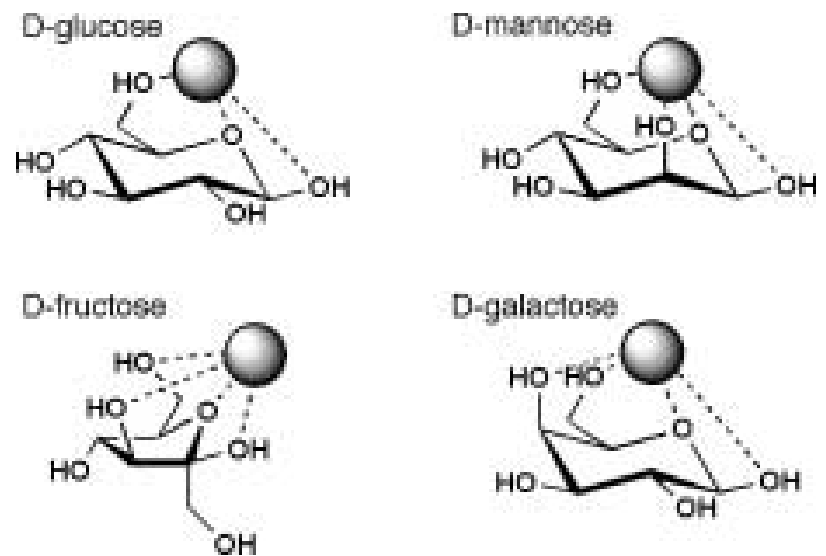

Fig. 3. $\beta$-D-glucose, $\beta$-D-mannose, $\beta$-D-fructose, and $\beta$-D-galactose bound to $\mathrm{Na}^{+}$. Structures generated from molecular modeling studies.

bidentate complex. These models are also consistent with the ESI-MS, ESI-MS/MS, and FAB-MS data where preferential $\mathrm{Na}^{+}$and $\mathrm{Li}^{+}$binding was found to occur in galactose, mannose and fructose.

\section{Conclusion}

These ESI, DIOS, and FAB-MS results suggest that the monosaccharides D-galactose, D-mannose, and D-fructose form more stable complexes with $\mathrm{Na}^{+}$and $\mathrm{Li}^{+}$than their structural isomer, D-glucose. The deuterated D-glucose analog was especially useful for studying relative cation binding affinities through monitoring ion intensities and in the heterodimer tandem mass analysis experiments. As shown with crown ethers [16] and suggested for sugars [32], the size of the cation and the number of available monosaccharide coordination sites is important for cation association. Previous experiments have demonstrated that both ESI and FAB-MS techniques are consistent with the thermodynamic properties and stabilities which host-guest complexes show in solution equilibrium. Results from these studies further indicate that there is continuity between the solution and gas phase behavior of these complexes. Most importantly, the determination of preferential binding affinities of cation-monosaccharide complexes may provide new information in the study of monosaccharide cellular transport, a process that is highly cation dependent.

\section{Experimental section}

\subsection{ESI-MS}

Electrospray experiments were performed on an API III PE Sciex triple-quadrupole mass spectrometer and a Finnigan LCQ mass spectrometer. Samples were infused at $4.0 \mu 1 / \mathrm{min}$ through a electrospray ionization source with a nozzle voltage of $5 \mathrm{kV}$. The instrument was tuned to unit mass resolution over a mass range dependent on the compounds being analyzed in each experiment. All spectra were acquired with PE Sciex Tune 3.0 software. In the association experiments, monosaccharide samples were analyzed in the presence of $\mathrm{Li}^{+}, \mathrm{Na}^{+}, \mathrm{K}^{+}, \mathrm{Rb}^{+}$, and $\mathrm{Cs}^{+}$. For all electrospray experiments, salt and monosaccharide sample concentrations were $100 \mu \mathrm{M}$. 


\subsection{Collision-induced dissociation}

Collision-induced dissociation (CID) experiments were performed with ultrapure argon as the collision gas at a target thickness of $6 \times 10^{14}$ atoms $/ \mathrm{cm}^{3}$ on the API-III. CID spectra were typically the result of averaging 40 to 60 scans. Sample concentrations were the same as noted above for the association experiments. In the case of the monosaccharide-cation complexes, the intensities of the parent ion and alkali cation fragment for each of the different cations and monosaccharides were compared to determine the binding preferences of the cations and monosaccharides. For the heterodimer experiments, MS/MS data elucidated the binding preference of each cation for either 6,6-glucose- $\mathrm{d}_{2}$ or the other monosaccharide (D-glucose, D-fructose, D-mannose, or D-galactose) involved in the heterodimer formation. The CID conditions provided predominantly single collisions and corresponded to $1.0( \pm 0.1) \mathrm{eV}$ collision energies in the center of mass reference frame. The collisional energies were adjusted by increasing and decreasing the velocity of the ions entering the collision cell or by varying the collision gas thickness.

\section{3. $F A B-M S$}

The FAB-MS data were obtained with a VG ZAB-VSE double focusing mass spectrometer equipped with a $35 \mathrm{kV}$ cesium ion gun. The instrument was tuned to a resolution of 2000 (10\% valley definition). Matrix conditions were established after testing glycerol and NBA matrices with water and methanol as co-solvents in the presence of these sugars. The NBA/methanol matrix gave the most intense and reproducible ion signals for the sugars with no observable fragmentation or formation of the [saccharide + cation + matrix $]^{+}$ions. Experiments were performed by applying $1.0 \mu \mathrm{l}$ of a 0.026 molar monosaccharide solution to $4 \mu \mathrm{l}$ of the $m$-nitrobenzyl alcohol (NBA) matrix. The salts were then introduced from a 0.026 equimolar methanol solution containing lithium, sodium, potassium, rubidium, and cesium iodide. In the cation competition experiments two monosaccharides were combined in a 0.026 equimolar solution and added to the matrix. A 0.026 molar methanol solution containing only one of the alkali iodide salts was then introduced to the matrix solution.

\subsection{DIOS-MS}

The DIOS-MS [37] measurements were performed in a PerSeptive Biosystems (Framingham, MA) Voyager STR time-of-flight reflectron mass spectrometer with delayed extraction. The DIOS chips were attached to the MALDI target plates using conductive carbon tape. Samples were irradiated with a nitrogen laser operated at $337 \mathrm{~nm}$ at $5 \mathrm{~Hz}$ ( 3 nanosecond pulse duration) and attenuated with a neutral density filter. Ions produced by laser desorption were energetically stabilized during a delayed extraction period of 150 nanoseconds and then accelerated through the linear time-of-flight mass analyzer by a $20 \mathrm{kV}$ potential pulse.

\subsection{MALDI-FTMS}

The MALDI-FTMS measurements were performed on an IonSpec mass spectrometer (Irvine, CA). Samples were irradiated with a Nd:YAG laser operated at the $3 \mathrm{rd}$ harmonic at $355 \mathrm{~nm}$ at $3 \mathrm{~Hz}(6 \mathrm{nanosec}-$ ond pulse duration) and attenuated with a neutral density filter. 


\subsection{Modeling}

Molecular modeling and reproductions described were performed and created using Chem3D Plus molecular modeling system from Cambridge Scientific Computing, Inc. The integrity of the calculations was based on published solution-phase NMR studies of the monosaccharides and was compared to MM2 calculations performed for the solution conformations.

\section{References}

[1] R.I. Sarker, W. Ogawa, M. Tsuda, S. Tanaka and T. Tsuchiya, Sequence of a Na+/glucose symporter gene and its flanking regions of vibrio parahaemolyticus, Biochimica et Biophysica Acta 1279 (1996), 149-156.

[2] X.Z. Chen, M.J. Coady, F. Jackson, A. Berteloot and J.Y. Lapointe, Thermodynamic determination of the Nat/glucose coupling ratio for the human SGLT1 cotransporter, Biophysical Journal 69 (1995), 2405-2414.

[3] G.A. Ahearn and L.P. Clay, Comparative Biochemistry and Physiology. A: Comparative Physiology 90 (1988), $627-634$.

[4] J.S. Flier, P. Usher and M. Deluise, Diabetes 30 (1981), 975-978.

[5] B.A. Hirayama, D.D. Loo and E.M. Wright, Cation effects on protein conformation and transport in the Nat/glucose cotransporter, J. Biol. Chem. 272 (1997), 2110-2115.

[6] K.J. Light-Wahl, B.L. Schwartz and R.D. Smith, Observation of the noncovalent quaternary associations of proteins by electrospray ionization mass spectrometry, J. Am. Chem. Soc. 116 (1994), 5271-5278.

[7] K.J. Light-Wahl, D.L. Springer, B.E. Winger, C.G. Edmonds, D.G., Camp II, B.D. Thrall and R.D. Smith, Observation of a small oligonucleotide duplex by electrospray ionization mass spectrometry, J. Am. Chem. Soc. 115 (1993), 803-804.

[8] G. Siuzdak, J.F. Krebs, S.J. Benkovic and H.J. Dyson, Binding of hapten to a single-chain catalytic antibody demonstrated by electrospray mass spectrometry, J. Am. Chem. Soc. 117 (1994), 7937-7938.

[9] M. Baca and S.B.H. Kent, Observation of a ternary complex between the dimeric enzyme Hiv-1 protease and a substratebased inhibitor, J. Am. Chem. Soc. 114 (1992), 3992-3993.

[10] B. Ganem, Y.T. Li and J.D. Henion, Detection of noncovalent receptor ligand complexes by mass spectrometry, J. Am. Chem. Soc. 113 (1991), 6294-6296.

[11] H. Zhang, I.-H. Chu, S. Leming and D.V. Dearden, Gas-phase molecular recognition - gas-phase crown ether alkali metal ion complexes and their reactions with neutral crowns, J. Am. Chem. Soc. 113 (1991), 7415-7417.

[12] N. Malhotra, P. Roepstorff, T.K. Hansen and J. Becher, Alkali metal ion complexation of crown ethersand related ligands studied by californium-252 plasma desorption mass spectrometry, J. Am. Chem. Soc. 112 (1990), 3709-3710.

[13] G. Bonas, C. Bosso and M.R. Vignon, Determination of the stability constants of macrocyclic ligand alkali cation complexes by fast atom bombardment mass spectrometry, Rapid Commun. Mass Spectrom. 2 (1988), 88.

[14] G. Siuzdak, S.V. Wendeborn and K.C. Nicolaou, Cationization of organometallo carbonyl compounds by fast ion bombardment, Int. J. Mass Spectrom. Ion Proc. 112 (1992), 79-91.

[15] (a) R.P. Grese and M.L. Gross, Gas-phase interactions of lithium ions and dipeptides, J. Am. Chem. Soc. 11 (1992), 5098-5104. (b) L.M. Teesch, R.C. Orlando and J. Adams, J. Am. Chem. Soc. 113 (1991), 3668.

[16] S. Lee, T. Wyttenbach, G. von Helden and M.T. Bowers, Gas phase conformations of $\mathrm{Li}^{+}, \mathrm{Na}^{+}, \mathrm{K}^{+}$and $\mathrm{Cs}^{+}$complexed with 18-crown-6, J. Am. Chem. Soc. 117 (1995), 10 159-10 160.

[17] G. Siuzdak, Y. Ichikawa, B. Munoz, T.J. Caulfield, C.-H. Wong and K.C. Nicolaou, Evidence of $\mathrm{Ca}_{2}^{+}$-dependent carbohydrate association through ion spray mass spectrometry, J. Am. Chem. Soc. 115 (1993), 2877-2881.

[18] J.W. Sam, X.J. Tang and J. Peisach, Electrospray mass spectrometry of iron bleomycin - demonstration that activated bleomycin is a ferric peroxide complex, J. Am. Chem. Soc. 116 (1994), 5250-5256.

[19] M. Sawada, L. Ouyang, Y. Takai, H. Yamada and T. Hanafusa, Complexation between saccharide and ammonium ion in gas phase - regarding stereochemical effects of methoxy groups at permethylated monosaccharides on stabilities of cluster ions in FAB mass spectrometry, Chem. Lett. 10 (1989), 1743-1746.

[20] M. Sawada, L. Ouyang, Y. Takai, H. Yamada, M. Shizuma, T. Kinoshita, T. Mochizuki and T. Hanafusa, 1-1 Adduct ion formation of permethylated monosaccharides with organic cations in FAB mass spectrometry, Bull. Chem. Soc. Jpn. 64 (1991), 1243-1252.

[21] A. Staempfli, Z.R. Zhou and J.A. Leary, Gas-phase dissociation mechanisms of dilithiated disaccharides - tandem mass spectrometry and semiempirical calculations, J. Org. Chem. 57 (1992), 3590-3594.

[22] A. Fura and J.A. Leary, Differentiation of $\mathrm{Ca}^{2+}$-coordinated and $\mathrm{Mg}^{2+}$-coordinated branched trisaccharide isomers - an electrospray ionization and tandem mass spectrometry study, Anal. Chem. 65 (1993), 2805-2811.

[23] M. Kohler and J.A. Leary, LC/MS/MS of carbohydrates with postcolumn addition of metal chlorides using a triaxial electrospray probe, Anal. Chem. 67 (1995), 3501-3508. 
[24] M. Sawada, Y. Okumura, M. Shizuma, Y. Takai, Y. Hidaka, H. Yamada, T. Tanaka, T. Kaneda, K. Hirose, S. Misumi and S. Takahashi, Enantioselective complexation of carbohydrate or crown ether hosts with organic ammonium ion guests detected by FAB mass spectrometry, J. Am. Chem. Soc. 115 (1993), 7381-7388.

[25] M. Sawada, Y. Takai, H. Yamada, S. Hirayama, T. Kaneda, T. Tanaka, K. Kamada, T. Mizooku, S. Takeuchi, K. Ueno, K. Hirose, Y. Tobe and K. Naemura, Chiral recognition in host-guest complexation determined by the enantiomer-labeled guest method using fast atom bombardment mass spectrometry, J. Am. Chem. Soc. 117 (1995), 7726-7736.

[26] G. Hofmeister and J.A. Leary, Chiral recognition of lithium-coordinated DIOLS using tandem mass spectrometry, Organic Mass Spectrometry 26 (1991), 811-812.

[27] G. Puzo, J.-J. Fournie and J.-C. Promé, Anal. Chem. 57 (1985), 892-894.

[28] H. Desaire and J.A. Leary, The effects of coordination number and ligand size on the gas phase dissociation and stereochemical differentiation of cobalt-coordinated monosaccharides, Intern. J. Mass Spectrom. 209 (2001), 171-184.

[29] S.J. Angyal and K.P. Davies, Chem. Commun. 1971, 500-501.

[30] S.J. Angyal, Aust. J. Chem. 25 (1972), 1957-1966.

[31] A.W. Roczko, S.K. Viswanadham, A.G. Sharkey and D.M. Hercules, Study of cationization of saccharides by laser mass spectrometry, Fresenius Z. Anal. Chem. 334 (1989), 521-526.

[32] S.J. Angyal, Adv. Carbohydr. Chem. Biochem. 47 (1989), 1-43.

[33] S.J. Angyal, Complexes of carbohydrates with metal cations. XIX - the effect of the size of the cation and of the interoxygen distances, Australian Journal of Chemistry 53 (2000), 567-570.

[34] R.D. Shannon, Acta Crystallogr., Sect. A 32 (1976), 751-767.

[35] V. Kovacik, J. Hirsch, D. Thölmann and H.-F. Grützmacher, Fourier transform ion cyclotron resonance. Study of ionmolecule reactions of [M-OCH3]+ ions of methyl 2,3,4,6-tetra-O-methyl-D-hexopyranosides with ammonia, Org. Mass Spectrom. 26 (1991), 1085-1088.

[36] C.F.G.C. Geraldes and M.M.C.A. Castro, Multinuclear NMR study of the interaction of vanadate with mononucleotides, ADP, and ATP, J. Inorg. Biochem. 35 (1989), 79-93.

[37] J. Wei, J.M. Buriak and G. Siuzdak, Desorption-ionization mass spectrometry on porous silicon, Nature 399 (1999), $243-246$. 


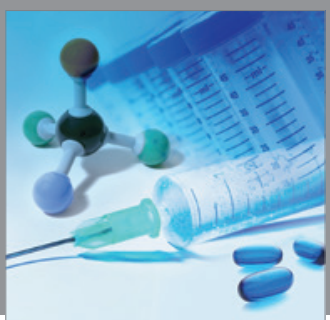

International Journal of

Medicinal Chemistry

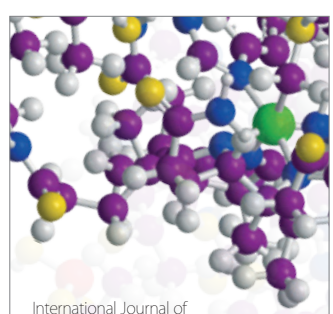

Carbohydrate Chemistry

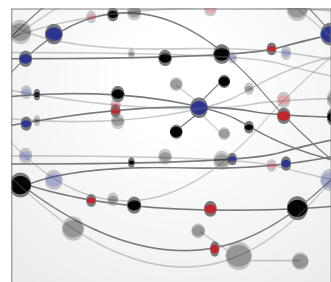

The Scientific World Journal
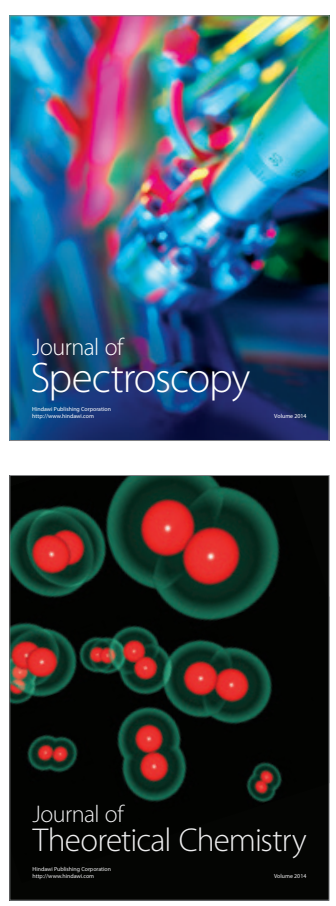
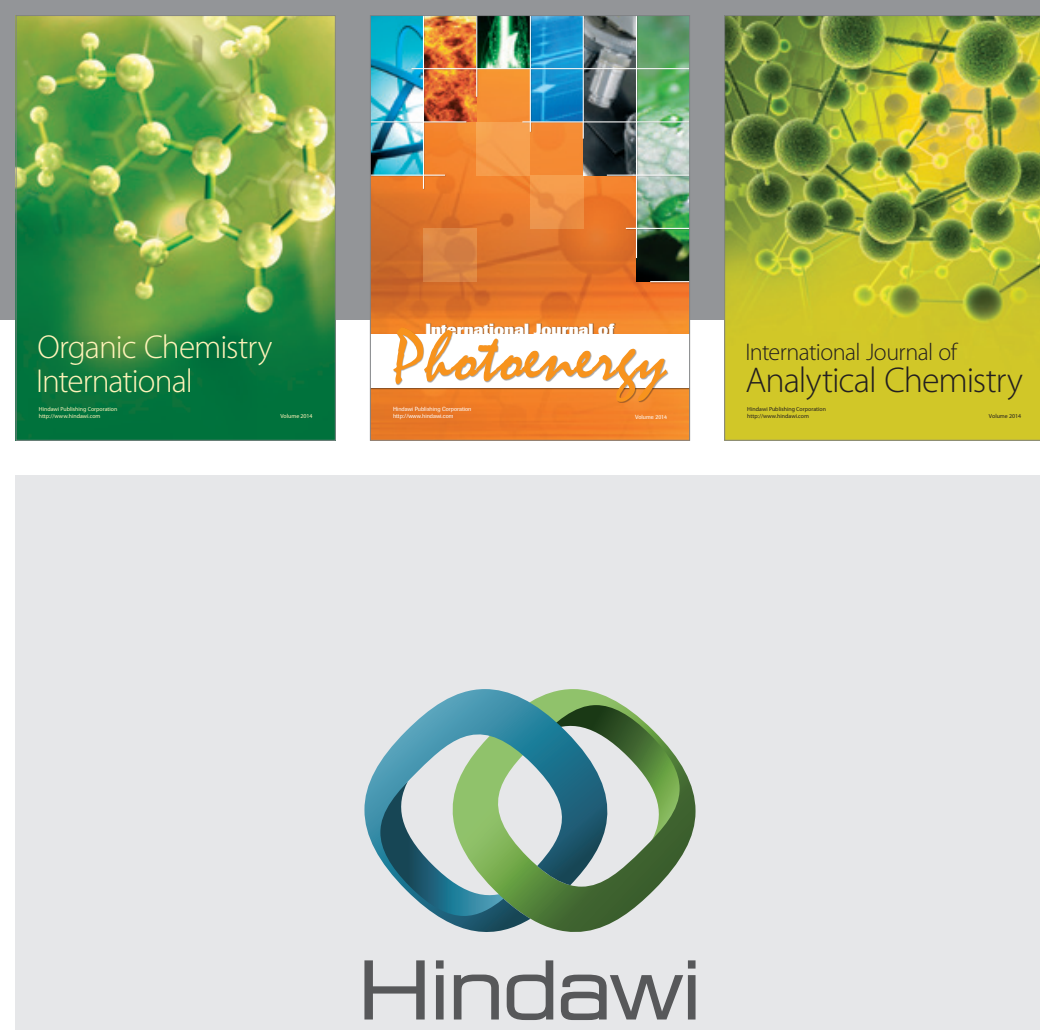

Submit your manuscripts at

http://www.hindawi.com
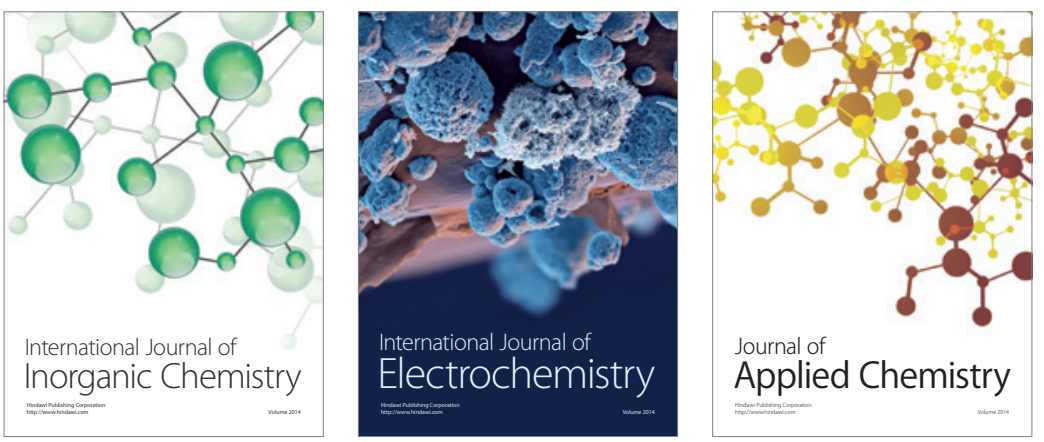

Journal of

Applied Chemistry
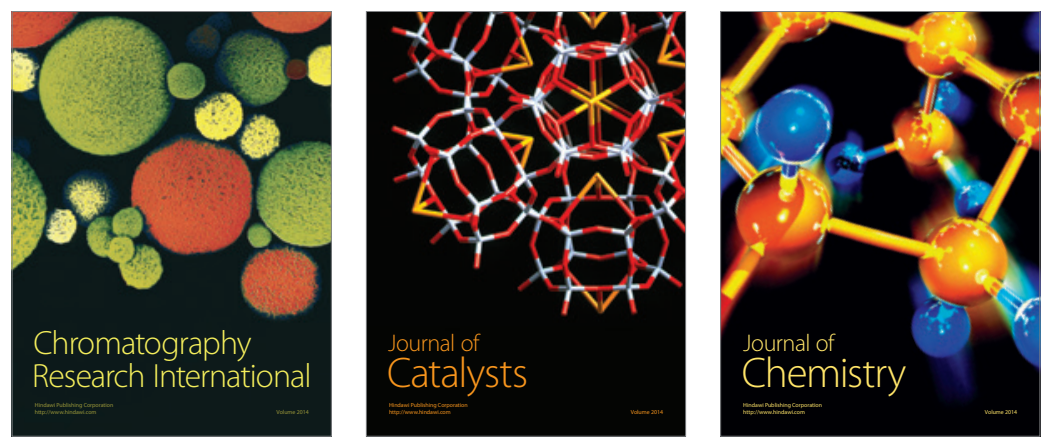
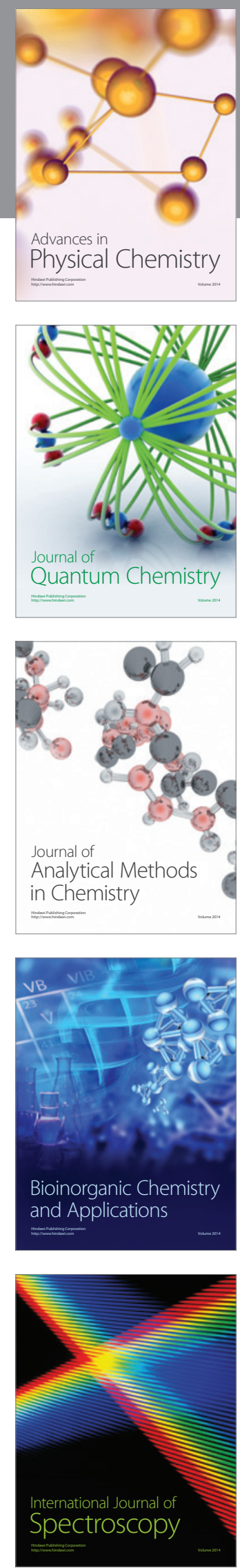